\title{
BMJ Open Assessing whether early attention of very preterm infants can be improved by an omega-3 long-chain polyunsaturated fatty acid intervention: a follow-up of a randomised controlled trial
}

Jacqueline F Gould, ${ }^{1,2}$ John Colombo, ${ }^{3,4}$ Carmel T Collins, ${ }^{1,5}$ Maria Makrides, ${ }^{1,5}$ Erandi Hewawasam, ${ }^{6}$ Lisa G Smithers ${ }^{7}$

To cite: Gould JF, Colombo J, Collins CT, et al. Assessing whether early attention of very preterm infants can be improved by an omega-3 long-chain polyunsaturated fatty acid intervention: a follow-up of a randomised controlled trial. BMJ Open 2018;8:e020043. doi:10.1136/ bmjopen-2017-020043

- Prepublication history and additional material for this paper are available online. To view these files, please visit the journal online (http://dx.doi. org/10.1136/bmjopen-2017020043).

Received 12 0ctober 2017 Revised 18 January 2018 Accepted 26 January 2018

Check for updates

For numbered affiliations see end of article.

Correspondence to Dr Jacqueline F Gould; jacqueline.gould@sahmri.com

\section{ABSTRACT}

Introduction Docosahexaenoic acid (DHA) accumulates in the frontal lobes (responsible for higher-order cognitive skills) of the fetal brain during the last trimester of pregnancy. Infants born preterm miss some of this in utero provision of DHA, and have an increased risk of suboptimal neurodevelopment. It is thought that supplementing infants born preterm with DHA may improve developmental outcomes. The aim of this follow-up is to determine whether DHA supplementation in infants born preterm can improve areas of the brain associated with frontal lobe function, namely attention and distractibility.

Methods and analysis We will assess a subset of children from the N-3 (omega-3) Fatty Acids for Improvement in Respiratory Outcomes (N3RO) multicentre double-blind randomised controlled trial of DHA supplementation. Infants born $<29$ weeks' completed gestation were randomised to receive an enteral emulsion containing $60 \mathrm{mg} / \mathrm{kg} /$ day of DHA or a control emulsion from within the first 3 days of enteral feeding until 36 weeks' postmenstrual age. Children will undergo multiple measures of attention at 18 months' corrected age. The primary outcome is the average time to be distracted when attention is focused on a toy. Secondary outcomes are other aspects of attention, and (where possible) an assessment of cognition, language and motor development with the Bayley Scales of Infant and Toddler Development, Third Edition. A minimum of 72 children will be assessed to ensure $85 \%$ power to detect an effect on the primary outcome. Families, and research personnel are blinded to group assignment. All analyses will be conducted according to the intentionto-treat principal.

Ethics and dissemination All procedures were approved by the relevant institutional ethics committees prior to commencement of the study. Results will be disseminated in peer-reviewed journal publications and academic presentations.

Trial registration number ACTRN12612000503820; Preresults.
Strengths and limitations of this study

- This follow-up study builds on a well-powered and well-conducted randomised controlled trial.

- A specialised assessment of early higher order cognitive functioning as well as a standardised global assessment will be used to evaluate efficacy of the intervention to effect brain development.

- No planned adjustments for multiple comparisons may be a limitation.

\section{INTRODUCTION}

\section{Brain development}

Brain development starts early during gestation and occurs in a lawful order, with rapid periods of change occurring in specific neurological regions at different times. During the first month following conception, brain development commences with the differentiation of neural progenitor cells (neural stem cells). The neural tube, consisting of the cells that become the nervous system, forms around 3-4 weeks' postconception. Once formed, the neural tube begins to differentiate into the structures that will become the spinal cord, the brain stem and cerebellum and the cerebral hemispheres. There is an intense period of neuronal proliferation ${ }^{1}$ and by the end of the embryonic period (conception to 8 weeks) the preliminary structures for the central nervous system, and peripheral nervous system, are distinctly present. ${ }^{2}$

During the fetal period (postconception week 9 until birth), dramatic brain growth results in the development of surface folds (the sulci) and ridges (the gyri) characteristic of the mature brain. During this period, 
nerve cells migrate to their final location within the brain (covering larger distances as the brain grows in size) and differentiate into their specialised mature features. ${ }^{23}$

A fetal brain 'growth spurt' starts at around midpregnancy (20 weeks' postconception) ${ }^{45}$ and continues until term (40 weeks' postconception). Functioning neurons transmit electrical impulses along their axons to communicate with other neurons through synapses. By the end of the second trimester (4-6 months), the majority of cells and structures are present, the cerebral cortex divides into two distinct hemispheres and some sensory information can be detected by the fetus.

During the last trimester (7-9 months), the brain roughly doubles in size from an estimated 125-375 $\mathrm{g}^{4}$ and the frontal lobes undergo an intense period of growth. ${ }^{45}$ As neurons migrate to their final location within the brain, they extend axonal processes that make up neural networks for communication. ${ }^{2}$ Axonal networks eventually develop into the white matter of the brain when they are myelinated, while the neuronal cell bodies comprise the grey matter. Neural tissue increases in volume rapidly at a rate of approximately $22 \mathrm{~mL} /$ week. ${ }^{6}$ The gyri and sulci develop on the surface of the brain and the various neural structures become increasingly pronounced and refined. By term, the majority of neurons that will be present in adulthood have emerged. ${ }^{7}$ The abundance of cells created during early proliferative periods are reduced after birth. ${ }^{2}$

A new-born full-term baby has a brain that is approximately $400 \mathrm{~g}$, roughly $25 \%$ of its adult size. The brain of a term-born infant has over 100 billion neurons; approximately the same number as an adult brain, but has 10 times fewer connections between neurons. At term, the brainstem is fully functional and capable of regulating vital autonomic functions such as breathing, regulation of heart rate and body temperature, processing of some basic sensory input (ie, visual, touch, auditory) and coordination of some movement.

While the fetal period is the peak time for brain growth, rapid development continues across the first two postnatal years so that by 24 months of age the brain is $80 \%$ of its adult weight. ${ }^{8}$ Myelination (the process whereby myelin, a fatty sheath, wraps around an axon) speeds up the rate an electrical impulse will pass along the axon. Synaptogenesis (creation of synapses), and pruning of unused excess synapses are also major postnatal processes in brain development. ${ }^{2}$ Myelin is white and gives axonal pathways in the brain its characteristic appearance as 'white matter'. Each neuron can have connections with over 1000 other neurons. Synapses are created at a rapid rate during the first 3 years such that over this period, connectivity of the brain exceeds levels in the adult brain. ${ }^{9}$ Synapses are then subsequently either pruned or strengthened.

Myelination and synaptogenesis are thought to increase the rate of information processing and are localised to specific areas of the brain at specific times. Theoretically, these processes continually enable the attainment of new developmental milestones between birth and early childhood. During infancy, myelination and synaptogenesis processes are restricted to sensory and motor areas, followed by structures that contribute to aspects of language, memory, cognition and emotion. In the first 6 months of life, rapid advances in visual and auditory processing as well as motor skills will allow an infant to orient, recognise and track a familiar moving object or person. Over the course of 18 months, an infant will grow into an active, mobile toddler capable of eating solids, speaking in two-word sentences and expressing emotions.

One specific area of the brain that develops rapidly across the last trimester and first 24 postnatal months are the frontal lobes. They are considered to be the most recent neural structures to have evolved, and are the largest relative to body mass in humans (as compared with other animals. ${ }^{10} 11$ They are the last region of the brain to mature. ${ }^{811}$ They develop rapidly in utero and increase quickly in size from birth to 2 years of age with continued slower growth until young adulthood. ${ }^{11}$ The frontal lobes are thought to mediate higher order cognitive skills known as 'executive' functions. Such skills are thought to involve the ability to integrate and process information from numerous cortical and subcortical areas. Executive functions involve integrating information from various regions of the brain, such that attention and action can act in the service of future or present goals. The initial forms of this integration can be seen in the control of attention, and inhibition of processing task-irrelevant sensory input. Eventually, these integrative functions are manifest in terms of planning, problem solving, mental flexibility and decision-making; when applied to emotion or the execution of behaviour, these functions contribute to the concept of self-regulation. Executive functions emerge during the second year, and continue developing throughout childhood and into adolescence. ${ }^{8}$

\section{Nutrition and brain development}

The first 1000 days of life (conception through to 24 months of age) have been highlighted as a critical period of importance for nutrition and for brain development. ${ }^{12-14}$ Developmental processes are highly dependent on the timed presence of specific nutrients in sufficient quantities. Hence, nutrition is considered to be one of the most influential non-genetic factors affecting early brain development. The effects of prenatal malnutrition or specific micronutrient deficiencies can be difficult to compensate for later in childhood, even when nutritional status is corrected. ${ }^{1516}$

Observational studies often show links between exposure to (or lack of) specific nutrients during pregnancy or infancy and child brain development. ${ }^{17-22}$ General malnutrition (lack of calories, protein) in childhood is associated with impairments in intellectual abilities, work capacity, educational achievement behavioural functioning and even delayed mental and motor development up to adolescence ${ }^{23}$ and severe child malnutrition has been linked to lower IQ, poorer cognitive function, lower academic performance and more behaviour problems. ${ }^{24}$ 
Iron-deficiency anaemia in the first 1000 days of life results in an increased risk of poor cognitive, motor, social-emotional, language, behavioural and neurophysiological development as well as a 6-15 point drop in developmental test scores compared with iron-sufficient infants, with deficits in cognition and school achievement lasting into adolescence. ${ }^{25} \mathrm{~A}$ meta-analysis of observational studies showed that individuals who lived in iodine-deficient areas scored 13.5 IQ points lower than individuals in iodine-sufficient areas. ${ }^{26}$ Zinc deficiency during pregnancy and lactation has been linked to congenital abnormalities and deficiency in children is associated with apathy and lethargy, reduced learning capacity and even mental retardation. ${ }^{27}$

Much has been learnt about the effects of nutritional deficiencies on brain development from observational studies of populations with endemic deficiency. However, given the concurrence of nutritional deficiencies with other risk factors for suboptimal development such as poor sanitation, education and healthcare as well as poverty, randomised controlled trials (RCTs) are needed to provide causal evidence. Benefit from nutritional supplements has been difficult to elucidate with prenatal, postnatal and infant intervention (range of individual nutrients, macronutrients or multiple micronutrients) trials often showing no effect on brain development, ${ }^{28-63}$ even in populations with endemic deficiencies. 31 37-39 44-46 48 51-54

\section{Assessing early neurodevelopment}

One of the primary reasons thought to contribute to the lack of detectable effects after intervention is the sensitivity of outcome measures to nutritional influence. A single-nutrient intervention is likely to have a relatively modest effect on early brain development in a generally well-nourished population. Most intervention studies use global tests of early development, such as the Bayley Scales of Infant Development (now third edition). ${ }^{64}$ These are standardised in their administration, scoring and interpretation, they have direct relevance to clinical practice and they allow comparability between the results of studies. However, they are designed for use in the clinical setting to detect problematic development and assign intervention. Scores are standardised so that the performance of an infant or child undergoing assessment can be compared with the expected abilities typical of children at that age. Hence, these tests are well adapted for detecting delay but not for detecting small differences in abilities between normally developing children. Additionally, by summing abilities across multiple neurodevelopmental domains, outcome scores on global tests may lack the sensitivity to detect differences in specific neural functions. ${ }^{65} \mathrm{~A}$ wider range of tests with more specificity is available to assess the functioning of older children; however, follow-up of RCTs longitudinally is costly and at risk of attrition bias.

To adequately evaluate the efficacy of nutritional interventions to impact early neurodevelopment, there are recommendations that researchers use assessment measures that involve the specific neurological domains hypothesised to be influenced by dietary manipulation. ${ }^{65-67}$ In the case of nutrition in the first 1000 days, an assessment of early frontal lobe functioning would be appropriate.

Executive function skills have recently become of interest to developmental researchers as it is possible to conduct behavioural assessments of executive functions from a young age, they are governed by the frontal lobes and they play a role in the development of cognition and social skills. ${ }^{68}{ }^{69}$ Some have shown that variation within the (hypothesised) normal range of development of executive function skills can be predictive of meaningful outcomes such as children's theory of mind (ability to reason about the mental states of others and self) ${ }^{69}{ }^{70}$ which has been implicated in preadolescent social competence. ${ }^{71}$ Attention is an executive function that has been of particular interest to researchers, and assessments of early attention show promise for assessing the efficacy of prenatal and early infant nutrition interventions to enhance brain development.

The construct of attention covers multiple processes, with the most commonly studied and recognised being endogenous attention. ${ }^{72}$ Endogenous attention is an individual's control over the allocation of attention to a stimulus, object or event, based on internal processes. ${ }^{72}$ Control of attention refers to direction and maintenance of attention towards central, focal stimulus and inhibition of sensory input from non-relevant or peripheral stimuli. Importantly, this involves the ability to maintain attentional focus to a target stimulus while resisting distracting stimuli.

Attention has a well-documented functional development in the developmental psychology literature and has been found to be predictive of later outcomes. ${ }^{73}$ Visual attention is largely exogenously driven during early infancy; fixations are automatically drawn to stimuli from the first day of life. ${ }^{74-76}$ For example, movement in the visual periphery will result in the automatic redirection of infant gaze or fixation. This type of attention is orienting and investigative and may facilitate infant learning. ${ }^{74}$ Basic endogenous attentional control emerges at the end of the first year and is signified by the infant's ability to actively select which stimuli to attend. ${ }^{72} 74$ The ability to sustain attention (ie, inhibit the impulse to shift the focus of attention) develops at about 12 months of age, allowing toddlers to engage with complex toys, although they can still be easily distracted by novel stimuli. ${ }^{72} 74$ When attention is engaged and sustained, it can be differentiated from more casual forms of attending through autonomic measures such as heart rate. ${ }^{74} 76$ Looking during periods when heart rate is not decelerated may reflect a lower quality or lesser amount of information processing. ${ }^{767}$

Early visual attention can also be measured by providing an infant or child with a toy to play with freely while recording their eye contact with the toy and/or heart 
rate. ${ }^{79-85}$ Independent play with toys provides an opportunity to observe changes in the child's spontaneous ability to focus attention and resist distraction. Historically, measures of attention in infants and children have explored the development of attention in early childhood, ${ }^{80-85}$ and associations of attention with later developmental outcomes. ${ }^{8687}$

Gains in attention regulation (such as ability to divide attention between stimuli, focus on important stimuli and inhibit distraction) has been found to predict growth in emergent literacy, vocabulary and math skills over the prekindergarten year ${ }^{86}$ and is essential for enhancing and facilitating learning. ${ }^{736}$ Two reviews have concluded that measures of attention in infancy are closely related to concurrent and later outcomes of traditional psychometric assessments of intelligence and language ${ }^{7588}$ Poor attention at the beginning of kindergarten age (4 years 10 months to 5 years 11 months) has been shown to be associated with lower academic achievement and peer rejection when entering kindergarten. ${ }^{87}$

The executive control of attention has been linked to frontal lobe functioning in a number of studies. ${ }^{89-91}$ Resisting distraction (a component of the ability to sustain attention on a focal point in the face of competing stimuli) is also thought to be mediated by frontal lobe structures; adults with damage to the frontal cortex often have difficulty maintaining attention to a conversation within a noisy crowded room. ${ }^{92} 93$

Colombo et al were the first to adapt the various age-appropriate typical measures of infant attention from the developmental psychology literature for assessing efficacy of a nutritional intervention. ${ }^{79}$ The investigators were able to demonstrate an association between fetal docosahexaenoic acid (DHA) exposure and favourable outcomes across multiple attention abilities in infants 4, 6, 8, 12 and 18 months of age. ${ }^{79} 81$ Since then, the attention assessment (or aspects of it) has been applied to infants in trials of zinc supplements, ${ }^{54}$ sphingomyelin fortified milk ${ }^{94}$ and omega-3 fatty acid intervention, ${ }^{41}{ }^{95}$ as well as RCTs of DHA during pregnancy. ${ }^{96} 97$

\section{Docosahexaenoic acid and brain development}

The brain is roughly $10 \%$ lipids (such as sterols (cholesterol), and omega-3, omega-6 and omega-9 fatty acids) that serve as functional components of cellular membranes. ${ }^{98-100}$ DHA is an omega-3 long-chain polyunsaturated fatty acid (LCPUFA) found in fish oil. It has been of great interest to nutritional researchers in recent years due to its hypothesised role in the brain, and in neural tissue development. DHA is a structural component of the phospholipid bilayer of cell membranes where it plays an integral role in membrane fluidity. ${ }^{101}$ Although present in all human cell membranes, DHA is concentrated in the cells of the central nervous system, particularly the brain, where it is a prominent fatty acid. ${ }^{102}{ }^{103}$ DHA accumulates in neural tissues throughout fetal, neonatal, infant and childhood development but is accrued at the greatest velocity during the last trimester of pregnancy ${ }^{104}$ during the peak period of rapid and intense brain growth. ${ }^{45}$

High concentrations of DHA have been shown to accumulate in the cerebral cortex and synapses of mice, rats, baboons and other mammals. ${ }^{105-107}$ Depriving animals of all omega-3 fatty acids leads to reduced brain tissue DHA $^{108-112}$ as well as less DHA incorporated into the fetal rat growth cone, ${ }^{113}$ with compensatory increases in omega-6 fatty acid levels ${ }^{112} 114$ particularly in the frontal lobes. ${ }^{115} 116$ In one rat study, severe omega-3 fatty acid deprivation during gestation lead to modified catecholamine biosynthesis in the brain and induced behavioural disturbances and decreased learning in the offspring. ${ }^{117}$ Other animal studies have linked omega-3 fatty acid deprivation to poorer orientation and motor skills, ${ }^{118}$ losses in spatial memory, lower cognitive and learning abilities $^{110}$ as well as lower performance on memory tasks and complex learning behaviours, ${ }^{116}{ }^{119}$ suggesting deficits in abilities that reflect the functioning of the frontal lobes. ${ }^{110116119}$ Human deprivation of omega-3 fatty acids at the same severity of deprivation in these animal studies is highly unlikely to occur; however, the animal models establish the importance of DHA for brain function.

It has been estimated that the human fetus acquires $\sim 70 \mathrm{mg}$ of omega-3 LCPUFA, largely as DHA, per day during the spurt of rapid growth in the last trimester. ${ }^{120}$ The DHA requirement of the fetus is thought to exceed the DHA intake of pregnant women consuming Western diets, with observational studies linking increased DHA intake (from seafood) in pregnancy to enhanced vocabulary comprehension, ${ }^{121}$ receptive vocabulary ${ }^{21}$ and verbal $\mathrm{IQ}^{20122}$ and that consuming more than the recommended quantity of fish during pregnancy is associated with higher child cognitive scores. ${ }^{20123}$ However, RCTs of DHA supplementation during pregnancy show little, if any, advantage to child neurodevelopment outcomes. ${ }^{29}$ It may be that prenatal DHA supplementation has no benefit for children's cognitive outcomes because fetal neurological structures of the brain are protected in utero. Preferential transfer of DHA across the placenta ${ }^{124} 125$ upregulation of maternal DHA synthesis during pregnancy and maternal stores of DHA ${ }^{126}$ may protect the DHA supply to the fetus. Most prenatal DHA RCTs have been restricted to infants born after a full gestation and hence only involve children who have had the benefit of the intrauterine supply of DHA during the peak period of fetal DHA accrual. ${ }^{104} 127$ However, infants born preterm are denied the maternal supply of DHA while the brain is undergoing rapid development.

\section{DHA and neurodevelopment of infants born preterm}

Children born preterm (born before 37 weeks' completed gestation) can be categorised as moderate-to-late preterm (32 to $<37$ weeks), very preterm (28 to $<32$ weeks) or extremely preterm $(<28$ weeks $) .{ }^{128}$ Advances in clinical practice have led to increased survival rates of infants born preterm; however, the prevalence of neurological deficits has not decreased. ${ }^{129} 130$ The rapid period of brain 
development that normally occurs in utero happens after birth in infants born very or extremely preterm. Between 29 and 40 weeks' (term equivalent) postmenstrual age, the brain grows from 150 to $400 \mathrm{~mL}$. Growth and development are genetically preprogrammed to occur during this age range. Preterm neonates are vulnerable to malnutrition and nutrient-specific deficiencies due to their high nutritional requirements, limited gastric capacity and feeding challenges.

Children who were born preterm have a higher risk of deficits in cognition, ${ }^{131} 132$ behaviour ${ }^{131}{ }^{133-137}$ and attention ${ }^{138}$ when compared with their term-born counterparts. In a meta-analysis of case-control studies (7000 infants born between 1980 and 2009), the IQ of school-age children who were born preterm was 11.9 points lower (95\% CI 10.5 to 13.4 ) overall, and 13.9 points $(95 \% \mathrm{CI}$ 11.5 to 16.2 , almost 1 SD) lower in infants born $<28$ weeks than term-born controls. ${ }^{139}$ The risk of poor outcome increases as gestational age decreases. ${ }^{131} 140$ In infants born $<33$ weeks, it is estimated that the IQ decreases 1.5 points for every week born preterm. ${ }^{134}$ The lack of association between year of birth and IQ suggests that no gains in neurodevelopment have been made for infants born extremely preterm over the last 25 years. ${ }^{139}$ The most recent global report of 15 million preterm infants born in 2010 showed that $52 \%$ of survivors born $<28$ weeks' gestation have some form of neurodevelopmental disability. ${ }^{141}$

Inadequate nutrient availability, such as DHA, may contribute to the poor developmental outcomes of infants born preterm. Infants born preterm miss placental provisions and rely on breast milk or supplemented infant formula to meet their nutrient needs. However, the amount of DHA received in utero $(\sim 60 \mathrm{mg} / \mathrm{kg} /$ day $)$ is much higher than the level provided in breast milk or current standard preterm infant formula $(\sim 20 \mathrm{mg} / \mathrm{kg} /$ day). Fetal synthesis of DHA from its precursor fatty acid, alpha-linolenic acid, is low such that the fetus is dependent on the supply of DHA from the mother. ${ }^{142}$ Hence, infants born preterm who are deprived the full placental transfer of DHA that occurs during a term pregnancy have lower neural tissue DHA levels than term-born infants. ${ }^{104}$

Early studies of DHA supplementation for preterm infants were restricted to infants fed formula. Interventions compared formulas containing some DHA with formulas that contained no DHA. ${ }^{143-150}$ Findings of improvements to infant development of visual acuity after DHA intervention in some trials ${ }^{148149151}$ led to the standard practice of preterm infant formulas containing $\sim 0.3 \%$ of total fatty acids as DHA. This provides the same level of DHA as most breast milk in Western populations but does not match the normal in utero accretion.

Neurodevelopmental assessments of preterm infants in DHA intervention studies have inconsistent results. ${ }^{34} 35152$ Three possible factors that have contributed to the contradictory findings are (1) neurodevelopmental assessments include predominantly global assessments, such as the Bayleys Scales of Infant Development ${ }^{3435152}$ that lack the sensitivity and specificity to detect effects to the performance of the frontal lobe (where DHA normally accumulates rapidly during the last trimester of pregnancy); (2) feeding complications (new-born preterm infants can take up to 4 weeks to achieve full enteral feeds) resulting in delays to achieving the desired DHA dose, and are subject to feeding protocols which often differ between hospitals; (3) while breast feeding is supported as a source of great benefit to infants, it is not possible to control the dose of DHA received by the infant from breast milk as supplementing lactating women results in wide variation of DHA content in breast milk. ${ }^{153}$

\section{The present study: DHA for preterm infant neurodevelopment}

A novel method of DHA supplementation for preterm infants has recently been developed as part of the N-3 (omega-3) Fatty Acids for Improvement in Respiratory Outcomes (N3RO) trial. ${ }^{154155}$ This new intervention is an enteral emulsion that overcomes the issues of supplementation by allowing direct delivery of DHA at the desired dose within the first days of life. There is no need to wait until infants are on full enteral feeds as the emulsion is given through the feeding tube immediately prior to a milk feed.

This intervention has been administered in a RCT of infants born <29 weeks' gestation. ${ }^{154} 155$ These infants are a particularly high-risk population of children born preterm. Over half will have cognitive deficits, academic underachievement and behavioural problems. ${ }^{156}$ By school-age children who were born extremely preterm, when compared with children born at term, have: a 14-point lower IQ, as well as attention, memory, language, visual spatial, executive function and behaviour impairments; and poorer reading, spelling and mathematics. ${ }^{156}$ They are also the subgroup within the preterm population that is the most at risk of insufficient DHA accretion ${ }^{157}$ having missed 11 , and up to 16 , weeks of placental DHA transfer which cannot be replaced with current neonatal feeding practices. ${ }^{158}$ The N3RO RCT therefore offers a unique opportunity to examine the effects of DHA supplementation on attention in those infants most at risk.

The specialised assessment of attention in these N3RO infants provides an excellent opportunity to reveal the importance of DHA exposure for early brain development. Our objective is to evaluate whether DHA supplementation in infants born $<29$ weeks' gestation can affect areas of the brain associated with frontal lobe function, namely attention and distractibility.

\section{METHODS}

\section{Study design}

This study is a prospective follow-up of a subsample of infants from the N3RO RCT. Children will be invited to undergo an assessment when they are $18 \pm 3$ months of age (corrected age for preterm birth). All families, and study staff will remain blinded to group treatment allocation for the duration of the follow-up. 
The N3RO trial enrolled 1273 infants born <29 weeks' completed gestation from 13 centres in Australia, New Zealand and Singapore between 18 June 2012 and 30 September 2015. ${ }^{154} 155$ Infants were ineligible to enrol in the N3RO trial if they were participating in another fatty acid intervention trial, they had a major congenital or chromosomal abnormality, they were receiving intravenous lipids containing fish oil, or if a breast feeding mother was taking $>250 \mathrm{mg} /$ day DHA supplements. ${ }^{154} 155$

Infants were enrolled within 3 days of their first enteral feed and randomised to receive an enteral emulsion containing either $60 \mathrm{mg}$ of DHA per $\mathrm{kg}$ of body weight per day, or a control soy emulsion without DHA. DHA and control emulsions were identical in packaging, labelling, viscosity and colour. The intervention was administered from enrolment through to 36 weeks' postmenstrual age or discharge home (whichever occurred first). Randomisation was through a computer-generated schedule with stratification for centre, sex and gestational age ( $<27$ completed weeks' gestation or 27 to $<29$ weeks' gestation). Infants from multiple births were randomised individually. At randomisation, infants were assigned a unique study identification number with a corresponding unique study product identification number so that families as well as clinical and all study personnel were blinded to group allocation.

The primary outcome of the N3RO trial was physiological bronchopulmonary dysplasia assessed at 36 weeks' postmenstrual age or discharge home, whichever occurred first. ${ }^{154155}$

\section{Participants}

Children from the N3RO trial are eligible for inclusion in this 18-month follow-up if they were born at the Women's and Children's Hospital $(n=133)$, or the Flinders Medical Centre ( $\mathrm{n}=59)$, Adelaide, Australia. Appointments will be conducted in study clinics at the hospital and medical centre between 2015 and mid-2016. Children will be ineligible if they have died, if caregivers have withdrawn from the N3RO trial, if they are over 2.5 years corrected age when screened for the follow-up or have a medically diagnosed major pathology that would invalidate the assessment (eg, severe cerebral palsy). The primary outcome of this study is based on a child resisting auditory and visual distraction, and tracking child eye-movements, facial expression and hand movements while playing with a toy. Major pathologies will be excluded if they are likely to influence the child's abilities during the assessment, for example, blindness, deafness or difficulties with motor movements. Pathologies will be identified in the routine follow-up care of extremely preterm infants. An experienced neonatal clinician will review all identified pathologies and advise the likelihood of interference with performance in the assessments. Potential participants will be screened for eligibility until the sample specified in the sample size calculation is obtained.

\section{Measures}

\section{Background information}

Sociodemographic data (such as parental age, education, employment, gestational age, birth weight, sex) were collected for the N3RO trial at trial entry. Information regarding breast feeding, formula and consumption of DHA supplements and DHA-rich foods will be captured by a questionnaire completed via an interview at the 18-month appointment. Caregivers will be asked whether the child was ever breastfed (including putting the infant to the breast or giving expressed breast milk even just once), and if yes the age of the child when breast feeding ceased (multiple choice response with options ' $\leq 6$ months, 7-12 months, 13-18 months, older than 18 months and still breast feeding or unknown'). We will ask whether the child regularly received an infant formula after discharge from hospital, and if yes, caregivers will be asked to specify the name and brand of the primary formula used in the first 12 months so that DHA content can be included in analyses. Caregivers will be asked whether the child has consumed infant or toddler milk containing DHA, omega-3 egg, normal egg, fish, DHA-fortified foods (such as milk or yoghurt) or a supplement containing DHA in the week preceding the appointment. Caregivers will be asked to complete a Home Screening Questionnaire $^{159}$ at the time of the appointment.

\section{Attention assessment}

The attention assessments will be conducted in accordance with previous research and our assessment manual (see online supplementary file 1) ${ }^{79} 8196$ The assessments will take place in a plain, quiet room with children seated on their caregiver's lap. Parents will be asked to refrain from interacting with their child during attention tasks. JVC Enviro-S memory camcorders (GZ-MS120) will record the tasks so that data can be extracted after the assessment. A Soniq E23Z13AT2 23 inch HD LED LCD flat screen television will be positioned $1 \mathrm{~m}$ away from the child on a 45-degree viewing angle while a mirror behind the child reflects the television screen to the camcorder. All essential speech is preprepared as a standard script.

There are three attention tasks in the assessment for infants aged 18 months, each of which has one main outcome and four to five other outcomes. In each task, the child will be given a toy(s) to play with freely and eye movements to and from the toys will be measured.

First is the Single Object task, primarily assessing the ability to sustain attention to a single complex stimulus in the absence of competition or distraction. The child is given a single, complex toy with multiple buttons and functions (the Leapfrog My Discovery House) with which to play for $5 \mathrm{~min}$. The main outcome of the Single Object task is the proportion (\%) of time spent in attention (looking at the toy) during the $5 \mathrm{~min}$ of free-play. Other outcomes from the Single Object task are (1) total duration of time spent in attention (looking at the toy); (2) number of episodes of attention (looks to the toy); (3) average duration of episode of attention (average length 
of look to the toy); (4) length of the longest episode of attention (longest look to the toy).

The second task is the Multiple Object task, primarily measuring the ability to sustain attention to a stimulus (one toy) in the presence of continuous competition (four other toys). The child is given five toys (squeaking rubber frog, alligator with rattle, plane with wheels and a button for sound, plastic turtle with see through shell containing beads and three stackable Fisher-Price blocks) to play with simultaneously for $5 \mathrm{~min}$. The main outcome of the Multiple Object task is the number of shifts in attention (looking between the five toys). Other outcomes from the Multiple Object task are (1) total duration of time spent in attention (looking at the toys); (2) number of episodes of inattention (looks away from the toys); (3) average duration of episode of attention (average length of look to the toys, where shifting between toys counts as one look so long as there is no inattention); (4) proportion $(\%)$ of time spent in attention (looking at the toys); (5) length of the longest episode of attention (longest look to the toys, where shifting between toys counts as one look so long as there is no inattention).

The final task is the Distractibility task, primarily measuring the ability to maintain attention to a target object (the toy) in the presence of a distracting and competing stimulus (the television). The child is given four toys (plastic-pieces turtle with four detachable mini turtles, Fisher-Price Rock-a-Stack set of stackable rings, Fisher-Price shape sorter and a Fisher-Price plastic train set with buttons and removable blocks) to play with one at a time, for $3 \mathrm{~min}$ each. The television plays a DVD consisting of seven-second distractor segments (segments of various children's programmes) with pseudorandom 5-25 s intervals of black, blank screen in order to distract the child's attention from the toy. Consecutive segments are from different programmes so that there is no story line that a child can anticipate or follow. There are approximately eight distractor segments for the $3 \mathrm{~min}$ of playtime with each toy. The DVD is paused when toys were changed over, or if a toy falls on the floor and has to be retrieved.

At the onset of each distractor segment in the Distractibility task, the child's state of attention is coded as focused attention (looking at and concentrating on the toy and engaged in active learning), casual attention (looking at the toy but not engaged in active learning) or other (not looking at the toy). State of attention (focused or casual) is based on the combination of child facial expression (ie, furrowed brow (focused) or smiling (casual)) and behavioural manipulations of the toy (ie, small careful movements or explorations of a feature of the toy (focused) or large careless general movements (casual) ). ${ }^{72}$ The main outcome of the Distractibility task is the average latency to turn to the distractor during focused attention (how long the child takes to look at the television if a distractor segment started when the child's attention was focused on the toy, averaged across the four toys). Other outcomes from the Distractibility task (averaged across the four toys) are (1) proportion of times distracted (turned to the television when a distractor segment started) during focused attention; (2) average latency to turn to the distractor during casual attention; (3) proportion of times distracted during casual attention; (4) total duration of time spent looking at the distractor segments; (5) total duration of time spent looking at the television when there was no distractor segment.

Video recordings of each task will be downloaded to a computer and viewed after the appointment using Pinnacle Studio Plus (12th Edition) Video Editing Software with a built-in timer and a shuttle jog (Contour ShuttleExpress) for frame-by-frame viewing. This will be necessary to record the exact timing of eye-movements to and from the toys, and to and from the television. An individual 'episode' of attention (a look at the toy(s)) or inattention (looking away from the toy(s)) of any duration is included for the Distractibility task but is only counted if it is $\geq 1 \mathrm{~s}$ in duration in the Single Object task ${ }^{79}$ or $\geq 0.5 \mathrm{~s}$ in duration in the Multiple Object task. ${ }^{81}$ Any interruptions during free-play (such as parental interactions) that influence the child's actions will be coded as interference and not included as part of the assessment. Twenty five per cent of children will be coded by two people to verify agreement and stability of data extraction procedures. Data extraction reliability will be compared using paired samples t-tests, and two-tailed Pearson's paired samples correlations.

\section{Bayley Scales of Infant and Toddler Development, Third Edition (Bayley-III)}

The Bayley-III is a test of global development for children under 42 months. ${ }^{64}$ A psychologist-administered Cognitive Scale, Motor Scale and Language Scale are standardised according to corrected age to have mean of 100 and SD of 15 . The cognitive scale evaluates sensorimotor development, exploration and manipulation, object relatedness, concept formation, memory and simple problem solving. The language scale is a composite of receptive communication (verbal comprehension, vocabulary) and expressive communication (babbling, gesturing and utterances). The motor scale evaluates both gross and fine motor functioning. Extremely preterm children are assessed with the Bayley-III as part of their routine clinical care when they are 24 months' corrected age. Parent-rated Adaptive Behaviour and Social-Emotional Functioning scales are also available in the Bayley-III but will not be not administered.

\section{Procedure}

Families of eligible children will be sent a letter of invitation 2 months before their child's birthday, followed by a telephone call to book appointments. All appointments will be conducted in study-specific clinic rooms at the Women's and Children's Hospital and the Flinders Medical Centre. Consent, attention assessment and background questionnaires will take place at the appointment. 
Children in the N3RO trial from the Women's and Children's Hospital and Flinders Medical Centre are included in routine clinical follow-up care for preterm infants. This includes a Bayley-III assessment and general medical examination at approximately 24 months' corrected age. Bayley-III results from these assessments will be collected from the medical records of consenting participants for this study.

\section{Sample size}

To achieve $85 \%$ power to detect a difference of $0.8 \mathrm{~s}$ $(\mathrm{SD}=1 \mathrm{~s})$ in latency to turn to the distractor during focused attention, a minimum of 36 children per group need to be assessed (total 72). Previously, an average difference of $1.1 \mathrm{~s}$ in latency at 12 and 18 months of age was found between term-born children dichotomised into high and low maternal DHA level at birth. ${ }^{81}$ As the current follow-up will be analysed according to randomised allocation of DHA, and children will be 18 months of age, the expected difference is narrower. The power calculation accounts for a $19 \%$ inflation factor for clustering due to multiple births. The inflation for clustering is based on 18-month Bayley Scales of Infant Development results in another of our studies with twins and triplets who were born $<33$ weeks' gestation, ${ }^{160}$ where on average there were 1.28 children per mother and the intraclustering coefficient for Mental Development Index scores were 0.68.

\section{Statistical analysis and data management}

Data collected at the follow-up appointment will be in the form of hard copy questionnaires, video recordings and excel spreadsheets with the extracted data from the attention assessment. Data will be identified through the randomisation ID numbers assigned at enrolment into the N3RO trial. Hard copy data will be kept in a locked office at each site, and electronic data will be stored on secure servers at the South Australian Health and Medical Research Institute with access granted only to study staff. Documents will be retained for 30 years after study completion in accordance with data retention schedules with research involving minors, and afterwards will be destroyed through confidential document disposal.

All analyses will be conducted according to intentionto-treat principle and according to an a priori statistical analysis plan. Intervention groups will be dummy coded to allow analyses to be blinded to treatment group. Baseline data will be compared for consenters to the follow-up and non-consenters, as well as for consenters to the follow-up and the whole of the N3RO sample. Within the follow-up sample, baseline characteristics will be compared between the DHA group and the control group.

Outcomes of DHA group and control group children will be compared using generalised estimated equations to account for the clustering of multiple births. The primary outcome of this follow-up is the main outcome of the Distractibility task assessment: average latency to turn to the distractor during focused attention. Secondary outcomes include all other attention task outcomes, as well as results on the Bayley-III assessment. Longer latency to turn to the television and greater duration or proportion of time spent in attention is considered to indicate better attention abilities.

Analyses will be conducted unadjusted as well as adjusted (primary analyses used to draw conclusions about the intervention) for stratification variables (sex, centre, gestational age $<27$ completed weeks or 27 to $<29$ weeks at birth). No adjustment will be made for multiple preplanned comparisons to ensure possible effects are detectable.

\section{Ethical considerations and dissemination of results}

This study will be carried out in accordance with the Australian National Statement on Ethical Conduct in Research Involving Humans, which builds on the ethical codes of the Declaration of Helsinki and the Principles of International Conference on Harmonisation Good Clinical Practice (as adopted in Australia). The N3RO Trial and this follow-up are registered on the Australia and New Zealand Clinical Trial Registry (ANZCTR: ACTRN12612000503820).

Caregivers will be provided with a detailed information sheet about the study. Written informed consent will be obtained from all families participating in the trial prior to commencing any study procedures and caregivers will be provided with a copy of the signed consent form. All data collected will be treated with confidence and caregivers will be free to withdraw their children from the study at any time. No participants will be identified in the dissemination of study results.

The attention assessments will be conducted by a trained assessor and do not pose any apparent physical risk to children. The attention assessment is enjoyable for young children and given the short and engaging nature of the toys, children generally maintain interest and concentration throughout the assessment. If a child becomes upset or uncooperative during the assessment, the child will be given time to recover or parents offered the opportunity to return and complete the assessment on another occasion. The appointment will take roughly $45 \mathrm{~min}$ to do the attention assessment and complete the questionnaires.

Parents will be given AUD $\$ 20$ to cover travel/parking and child care expenses of other siblings not attending the appointment.

The results of this follow-up study will be published in peer-reviewed journals and presented at academic conferences. No individual participants will be identified or identifiable. All data will be analysed in deidentified form.

\section{DISCUSSION}

Attention is increasingly becoming an outcome of interest for researchers attempting to evaluate early nutritional interventions on brain development. ${ }^{4154798194-97161-163}$ However, at present the clinical 
relevance of the attention assessment is unknown. We will have the combined advantage of a specialised measure of early development, which has already shown sensitivity to early DHA exposure, ${ }^{79} 81$ as well as a standardised measure of global development. We will be able to compare performance on the attention assessment with results on the Bayley-III to explore the clinical implications for the measure of attention. It will also be important to assess these children at a later age with a standardised psychometric assessment to determine the ability of the attention assessment to predict later development, as well as the long-term outcome of the intervention. A possible limitation of the study design is that a subset of the 1273 children from the original trial from 2 of the 13 enrolling centres will be invited to participate in this follow-up, possibly introducing bias due to differences in populations and clinical care between enrolling centres. Participation in the follow-up will require attendance at a clinic appointment, possibly introducing further bias from attrition. However, the size of subsample was determined by a power calculation, we have no evidence of systematic differences in the intervention according to site, and we do not believe that the effect of DHA on attention will differ according to participation in the study. Characteristics of ineligible children and non-consenters will be compared with characteristics of consenters. It may also be noteworthy that the DHA intervention from the N3RO trial ceased at 36 weeks' postmenstrual age (or discharge home from the hospital-whichever occurred first) and infants subsequently received varying doses of DHA through formula or breastmilk. The risk of unbalanced intake of DHA between study groups during the last 4 weeks of the fetal brain growth spurt will need to be taken into account when considering study results. We hypothesise that providing the estimated in utero provisions of DHA to infants born $<29$ weeks' gestation will facilitate restoration of normal brain development and reduce deficits in early child visual attention, distractibility as well as general development captured by the Bayley-III.

\section{Author affiliations}

${ }^{1}$ Department of Healthy Mothers, Babies and Children, South Australian Health and Medical Research Institute, Adelaide, South Australia, Australia

${ }^{2}$ School of Psychology, Faculty of Health and Medical Sciences, The University of Adelaide, Adelaide, South Australia, Australia

${ }^{3}$ Schiefelbusch Institute for Life Span Studies and Department of Psychology, University of Kansas, Kansas, USA

${ }^{4}$ Dole Human Development Center, Lawrence, Kansas, USA

${ }^{5}$ Discipline of Paediatrics, Faculty of Health and Medical Sciences, The University of Adelaide, Adelaide, South Australia, Australia

${ }^{6}$ School of Agriculture, Food and Wine, Faculty of Sciences, The University of Adelaide, Adelaide, South Australia, Australia

${ }^{7}$ School of Public Health, Faculty of Health and Medical Sciences, The University of Adelaide, Adelaide, South Australia, Australia

Acknowledgements The authors would like to thank the families who generously participated in the N3RO Trial, the N3RO Steering Committee, the N3RO Investigative Team and research staff.
Contributors Study concept and design: JFG, MM, LGS, CTC, JC. Drafting the protocol: JFG, JC, LGS, CTC. Comment and approval of the final draft of the protocol: JFG, MM, LGS, CTC, JC, EH. Statistical expertise: LGS. Obtained funding: JFG, MM, LGS, CTC. Administrative, technical or material support: JFG, MM, CTC, EH.

Funding Financial support for the submitted work was from the National Health and Medical Research Council (NHMRC) Australia for the original trial (ID 1022112) and from a Women's and Children's Hospital Foundation Project Grant.

Competing interests Study product was donated by Clover Corporation Limited, Australia. JFG is supported by a Women's and Children's Hospital Foundation MS McLeod Research Fellowship. MM is supported by an Australian National Health and Medical Research Council (NHMRC) Senior Research Fellowship ID: 1061704 and CTC is supported by a NHMRC Translating Research into Practice (TRIP) Fellowship ID 1132596. Honoraria have been paid to JFG's institution to support conference travel by the Nestle Nutrition Institute. MM reports serving on scientific advisory boards for Nestle and Fonterra. Associated honoraria for MM are paid to her institution to support conference travel and continuing education for postgraduate students and early career researchers. JC also serves on scientific advisory boards for Nestle and Fonterra and is a consultant for Mead Johnson Nutrition. No other authors reported any financial disclosures. The contents of the published material are solely the responsibility of the authors and do not reflect the views of the NHMRC.

Patient consent Parental/guardian consent obtained.

Ethics approval All procedures and study materials have been reviewed and approved in writing by the Women's and Children's Health Network and Southern Adelaide Local Health Network Human Research Ethics Committees prior to study initiation at that site.

Provenance and peer review Not commissioned; externally peer reviewed.

Open Access This is an Open Access article distributed in accordance with the Creative Commons Attribution Non Commercial (CC BY-NC 4.0) license, which permits others to distribute, remix, adapt, build upon this work non-commercially, and license their derivative works on different terms, provided the original work is properly cited and the use is non-commercial. See: http://creativecommons.org/ licenses/by-nc/4.0/

(c) Article author(s) (or their employer(s) unless otherwise stated in the text of the article) 2018. All rights reserved. No commercial use is permitted unless otherwise expressly granted.

\section{REFERENCES}

1. Bystron I, Blakemore C, Rakic P. Development of the human cerebral cortex: boulder committee revisited. Nat Rev Neurosci 2008;9:110-22.

2. Stiles J, Jernigan TL. The basics of brain development. Neuropsychol Rev 2010;20:327-48.

3. Kostović I, Jovanov-Milosević N. The development of cerebral connections during the first 20-45 weeks' gestation. Semin Fetal Neonatal Med 2006;11:415-22.

4. Dobbing J, Sands J. Quantitative growth and development of human brain. Arch Dis Child 1973;48:757-67.

5. Volpe JJ. Neuronal proliferation, migration, organization, and myelination. In: W.B. Saunders Staff, ed. Neurology of the Newborn. 2nd edn. Philadelphia: W. B. Saunders Company, 1987:33-68.

6. Hüppi PS, Warfield S, Kikinis R, et al. Quantitative magnetic resonance imaging of brain development in premature and mature newborns. Ann Neurol 1998;43:224-35.

7. Johnson MH. Functional brain development in humans. Nat Rev Neurosci 2001;2:475-83.

8. Casey BJ, Giedd JN, Thomas KM. Structural and functional brain development and its relation to cognitive development. Biol Psychol 2000;54:241-57.

9. Innocenti GM, Price DJ. Exuberance in the development of cortical networks. Nat Rev Neurosci 2005;6:955-65.

10. Fuster JM. Frontal lobe and cognitive development. J Neurocytol 2002;31(3-5):373-85.

11. Dempster FN. The rise and fall of the inhibitory mechanism: toward a unified theory of cognitive development and aging. Developmental Review 1992;12:45-75.

12. Cusick S, Georgieff MK. The first 1,000 days of life: the brain's window of opportunity. Secondary the first 1,000 days of life: the brain's window of opportunity. https://www.unicef-irc.org/article/ 958/ (accessed 31 Aug 2017). 
13. Save the Children. Nutrition in the first 1,000 days; state of the world's mothers, 2012.

14. U.S. Agency for International Development. The 1,000-day window of opportunity: technical guidance brief Secondary The 1,000-day window of opportunity: technical guidance brief. $2017 \mathrm{https}: / / \mathrm{www}$. usaid.gov/what-we-do/global-health/nutrition/1000-day-windowopportunity (accessed 31 Aug 2017).

15. Dobbing J, Hopewell JW, Lynch A. Vulnerability of developing brain. VII. Permanent deficit of neurons in cerebral and cerebellar cortex following early mild undernutrition. Exp Neurol 1971;32:439-47.

16. Prado EL, Dewey KG. Nutrition and brain development in early life. Nutr Rev 2014;72:267-84.

17. Black MM. Micronutrient deficiencies and cognitive functioning. $J$ Nutr 2003;133(11 Suppl 2):3927S-31.

18. Morales E, Guxens M, Llop S, et al. Circulating 25-hydroxyvitamin D3 in pregnancy and infant neuropsychological development. Pediatrics 2012;130:e913-e920.

19. Zhu P, Tong SL, Hao JH, et al. Cord blood vitamin D and neurocognitive development are nonlinearly related in toddlers. $J$ Nutr 2015;145:1232-8.

20. Hibbeln JR, Davis JM, Steer C, et al. Maternal seafood consumption in pregnancy and neurodevelopmental outcomes in childhood (ALSPAC study): an observational cohort study. Lancet 2007;369:578-85.

21. Oken E, Radesky JS, Wright RO, et al. Maternal fish intake during pregnancy, blood mercury levels, and child cognition at age 3 years in a us cohort. Am J Epidemiol 2008;167:1171-81.

22. Berglund SK, Torres-Espínola FJ, García-Valdés L, et al. The impacts of maternal iron deficiency and being overweight during pregnancy on neurodevelopment of the offspring. Br J Nutr 2017;118:533-40.

23. Grantham-McGregor S, Baker-Henningham $\mathrm{H}$. Review of the evidence linking protein and energy to mental development. Public Health Nutr 2005;8:1191-201.

24. Grantham-McGregor S. A review of studies of the effect of severe malnutrition on mental development. J Nutr 1995;125(8 Suppl):2233S-8.

25. Lozoff B, Beard J, Connor J, et al. Long-lasting neural and behavioral effects of iron deficiency in infancy. Nutr Rev 2006;64(5 Pt 2):34-43.

26. Blelchrodt N, Born M. A metaanalysis of research on iodine and its relationship to cognitive development. In: Stanbury J, ed. The damaged brain of iodine deficiency New York: cognizant communication corporation, 1994:195-200.

27. Pfeiffer CC, Braverman ER, Zinc BER. Zinc, the brain and behavior. Biol Psychiatry 1982;17:513-32.

28. Gould JF. Complementary feeding, micronutrients and developmental outcomes of children. In: Black RE, Makrides M, Ong K, eds. Complementary feeding: building the foundations for a healthy life (nestle nutrition institute workshop series 87). Switzerland: Karger, 2017.

29. Gould JF, Smithers LG, Makrides M. The effect of maternal omega-3 (n-3) LCPUFA supplementation during pregnancy on early childhood cognitive and visual development: a systematic review and meta-analysis of randomized controlled trials. Am J Clin Nutr 2013;97:531-44.

30. Pasricha SR, Hayes E, Kalumba K, et al. Effect of daily iron supplementation on health in children aged 4-23 months: a systematic review and meta-analysis of randomised controlled trials. Lancet Glob Health 2013;1:e77-86.

31. Zhou SJ, Anderson AJ, Gibson RA, et al. Effect of iodine supplementation in pregnancy on child development and other clinical outcomes: a systematic review of randomized controlled trials. Am J Clin Nutr 2013;98:1241-54.

32. Jasani B, Simmer K, Patole SK, et al. Long chain polyunsaturated fatty acid supplementation in infants born at term. Cochrane Database Syst Rev 2017;3:Cd000376.

33. Zhou SJ, Gibson RA, Crowther CA, et al. Effect of iron supplementation during pregnancy on the intelligence quotient and behavior of children at $4 \mathrm{y}$ of age: long-term follow-up of a randomized controlled trial. Am J Clin Nutr 2006;83:1112-7.

34. Smithers LG, Gibson RA, McPhee A, et al. Effect of long-chain polyunsaturated fatty acid supplementation of preterm infants on disease risk and neurodevelopment: a systematic review of randomized controlled trials. Am J Clin Nutr 2008;87:912-20.

35. Schulzke SM, Patole SK, Simmer K. Long-chain polyunsaturated fatty acid supplementation in preterm infants. Cochrane Database Syst Rev 2011;2:CD000375.

36. Zimmermann MB. The effects of iodine deficiency in pregnancy and infancy. Paediatr Perinat Epidemiol 2012;26(Suppl 1):108-17.
37. Waber DP, Vuori-Christiansen L, Ortiz N, et al. Nutritional supplementation, maternal education, and cognitive development of infants at risk of malnutrition. Am J Clin Nutr 1981;34(Suppl 4):807-13

38. Husaini MA, Karyadi L, Husaini YK, et al. Developmental effects of short-term supplementary feeding in nutritionally-at-risk Indonesian infants. Am J Clin Nutr 1991;54:799-804.

39. Aburto NJ, Ramirez-Zea M, Neufeld LM, et al. The effect of nutritional supplementation on physical activity and exploratory behavior of Mexican infants aged 8-12 months. Eur J Clin Nutr 2010;64:644-51.

40. Auestad N, Halter R, Hall RT, et al. Growth and development in term infants fed long-chain polyunsaturated fatty acids: a doublemasked, randomized, parallel, prospective, multivariate study. Pediatrics 2001;108:372-81.

41. van der Merwe LF, Moore SE, Fulford AJ, et al. Long-chain PUFA supplementation in rural African infants: a randomized controlled trial of effects on gut integrity, growth, and cognitive development. Am J Clin Nutr 2013;97:45-57.

42. Phuka JC, Gladstone M, Maleta K, et al. Developmental outcomes among 18-month-old Malawians after a year of complementary feeding with lipid-based nutrient supplements or corn-soy flour. Matern Child Nutr 2012;8:239-48.

43. Drover JR, Felius J, Hoffman DR, et al. A randomized trial of DHA intake during infancy: school readiness and receptive vocabulary at 2-3.5 years of age. Early Hum Dev 2012;88:885-91.

44. Lozoff B, Brittenham GM, Viteri FE, et al. The effects of short-term oral iron therapy on developmental deficits in iron-deficient anemic infants. J Pediatr 1982;100:351-7.

45. Aukett MA, Parks YA, Scott PH, et al. Treatment with iron increases weight gain and psychomotor development. Arch Dis Child 1986;61:849-57.

46. Idjradinata P, Pollitt E. Reversal of developmental delays in irondeficient anaemic infants treated with iron. Lancet 1993;341:1-4.

47. Yalçin SS, Yurdakök K, Açikgöz D, et al. Short-term developmental outcome of iron prophylaxis in infants. Pediatr Int 2000;42:625-30.

48. Akman M, Cebeci D, Okur V, et al. The effects of iron deficiency on infants' developmental test performance. Acta Paediatr 2004;93:1391-6.

49. Cao XY, Jiang XM, Dou ZH, et al. Timing of vulnerability of the brain to iodine deficiency in endemic cretinism. N Engl J Med 1994;331:1739-44.

50. Trowbridge FL. Intellectual assessment in primitive societies, with a preliminary report of a study of the effects of early iodine supplementation on intelligence. Adv Exp Med Biol 1972;30:137-49.

51. Bentley ME, Caulfield LE, Ram M, et al. Zinc supplementation affects the activity patterns of rural Guatemalan infants. J Nutr 1997; 127:1333-8.

52. Gardner JM, Powell CA, Baker-Henningham $\mathrm{H}$, et al. Zinc supplementation and psychosocial stimulation: effects on the development of undernourished Jamaican children. Am J Clin Nutr 2005;82:399-405.

53. Taneja S, Bhandari N, Bahl R, et al. Impact of zinc supplementation on mental and psychomotor scores of children aged 12 to 18 months: a randomized, double-blind trial. $J$ Pediatr 2005;146:506-11.

54. Colombo J, Zavaleta N, Kannass KN, et al. Zinc supplementation sustained normative neurodevelopment in a randomized, controlled trial of Peruvian infants aged 6-18 months. J Nutr 2014;144:1298-305.

55. Brown KH, Peerson JM, Baker SK, et al. Preventive zinc supplementation among infants, preschoolers, and older prepubertal children. Food Nutr Bull 2009;30(1 Suppl):S12-40.

56. Wang YY, Wang FZ, Wang K, et al. [Effects of nutrient fortified complementary food supplements on development of infants and young children in poor rural area of Gansu Province]. Wei Sheng Yan Jiu 2006;35:772-4.

57. Katz J, Khatry SK, Leclerq SC, et al. Daily supplementation with iron plus folic acid, zinc, and their combination is not associated with younger age at first walking unassisted in malnourished preschool children from a deficient population in rural Nepal. $J$ Nutr 2010;140:1317-21.

58. Surkan PJ, Siegel EH, Patel SA, et al. Effects of zinc and iron supplementation fail to improve motor and language milestone scores of infants and toddlers. Nutrition 2013;29:542-8.

59. De-Regil LM, Suchdev PS, Vist GE, et al. Home fortification of foods with multiple micronutrient powders for health and nutrition in children under two years of age (Review). Evid Based Child Health 2013;8:112-201.

60. Kristjansson E, Francis DK, Liberato S, et al. Food supplementation for improving the physical and psychosocial health of socio- 
economically disadvantaged children aged three months to five years. Cochrane Database Syst Rev 2015:CD009924.

61. Ota E, Mori R, Middleton P, et al. Zinc supplementation for improving pregnancy and infant outcome. Cochrane Database Syst Rev 2015:CD000230

62. Haider BA, Bhutta ZA. Multiple-micronutrient supplementation for women during pregnancy. Cochrane Database Syst Rev 2015:CD004905.

63. Larson LM, Yousafzai AK. A meta-analysis of nutrition interventions on mental development of children under-two in low- and middleincome countries. Matern Child Nutr 2017;13:e12229.

64. Bayley N. Bayley scales of infant and toddler development-third edition. 3rd edn. San Antonio, TX: Pearson Education, Inc, 2006.

65. Wainwright PE, Colombo J. Nutrition and the development of cognitive functions: interpretation of behavioral studies in animals and human infants. Am J Clin Nutr 2006;84:961-70.

66. Cheatham CL, Colombo J, Carlson SE. N-3 fatty acids and cognitive and visual acuity development: methodologic and conceptual considerations. Am J Clin Nutr 2006;83(6 Suppl):1458S-66.

67. Georgieff MK. Nutrition and the developing brain: nutrient priorities and measurement. Am J Clin Nutr 2007;85(2):614S-20.

68. Blair C. School readiness. Integrating cognition and emotion in a neurobiological conceptualization of children's functioning at school entry. Am Psychol 2002;57:111-27.

69. Carlson SM, Moses LJ. Individual differences in inhibitory control and children's theory of mind. Child Dev 2001;72:1032-53.

70. Carlson SM, Mandell DJ, Williams L. Executive function and theory of mind: stability and prediction from ages 2 to 3. Dev Psychol 2004;40:1105-22.

71. Bosacki S, Wilde Astington J, Astington JW. Theory of mind in preadolescence: relations between social understanding and social competence. Soc Dev 1999;8:237-55.

72. Colombo J, Cheatham CL. The emergence and basis of endogenous attention in infancy and early childhood. Adv Child Dev Behav 2006;34:283-322.

73. Anderson V, Fenwick T, Manly T, et al. Attentional skills following traumatic brain injury in childhood: a componential analysis. Brain Inj 1998;12:937-49.

74. Ruff HA, Rothbart MK. Attention in early development; themes and variations. New York, USA: Oxford University Press, 1996.

75. Colombo J. The development of visual attention in infancy. Annu Rev Psychol 2001;52:337-67.

76. Colombo J. Infant attention grows up: the emergence of a developmental cognitive neuroscience perspective. Curr Dir Psychol Sci 2002;11:196-200.

77. Richards JE. The development of sustained visual attention in infants from 14 to 26 weeks of age. Psychophysiology 1985;22:409-16.

78. Johnson MH, Posner MI, Rothbart MK. Components of visual orienting in early infancy: contingency learning, anticipatory looking, and disengaging. J Cogn Neurosci 1991;3:335-44.

79. Colombo J, Kannass KN, Shaddy DJ, et al. Maternal DHA and the development of attention in infancy and toddlerhood. Child Dev 2004;75:1254-67.

80. Choi HP, Anderson DR. A temporal analysis of free toy play and distractibility in young children. J Exp Child Psychol 1991;52:41-69.

81. Kannass KN, Colombo J, Carlson SE. Maternal DHA levels and toddler free-play attention. Dev Neuropsychol 2009;34:159-74.

82. Anderson DR, Choi HP, Lorch EP. Attentional inertia reduces distractibility during young children's TV viewing. Child Dev 1987:58:798-806.

83. Tellinghuisen DJ, Oakes LM. Distractibility in infancy: the effects of distractor characteristics and type of attention. J Exp Child Psycho 1997:64:232-54.

84. Ruff HA, Lawson KR. Development of sustained, focused attention in young children during free play. Devl Psychol 1990;34:454-64.

85. Ruff HA, Capozzoli MC. Development of attention and distractibility in the first 4 years of life. Dev Psychol 2003;39:877-90.

86. McClelland MM, Cameron CE, Connor CM, et al. Links between behavioral regulation and preschoolers' literacy, vocabulary, and math skills. Dev Psychol 2007;43:947-59.

87. Vaughn S, Hogan A, Kouzekanani K, et al. Peer acceptance, selfperceptions, and social skills of learning disabled students prior to identification. J Educ Psychol 1990;82:101-6.

88. Bornstein MH, Sigman MD. Continuity in mental development from infancy. Child Dev 1986;57:251-74.

89. Goldman DZ, Shapiro EG, Nelson CA. Measurement of vigilance in 2-year-old children. Dev Neuropsychol 2004;25:227-50.

90. Bell MA. Frontal lobe function during infancy: implications for the development of cognition and attention. In: Richards
JE, ed. Cognitive neuroscience of attention; a developmental perspective. New Jersey, USA: Lawrence Erlbaum Associates, 1998:287-316.

91. Ruff HA. Summary and commentary. Selective attention: its measurement in a developmental framework. In: Richards JE, ed. Cognitive neuroscience of attention; a developmental perspective. New Jersey, USA: Lawrence Erlbaum Associates, 1998:419-26.

92. Guitton D, Buchtel HA, Douglas RM. Frontal lobe lesions in man cause difficulties in suppressing reflexive glances and in generating goal-directed saccades. Exp Brain Res 1985:58:455-72.

93. Arnsten AF, Neville HJ, Hillyard SA, et al. Naloxone increases electrophysiological measures of selective information processing in humans. J Neurosci 1984;4:2912-9.

94. Tanaka K, Hosozawa M, Kudo N, et al. The pilot study: sphingomyelin-fortified milk has a positive association with the neurobehavioural development of very low birth weight infants during infancy, randomized control trial. Brain Dev 2013;35:45-52.

95. Harbild HL, Harsløf LB, Christensen JH, et al. Fish oilsupplementation from 9 to 12 months of age affects infant attention in a free-play test and is related to change in blood pressure. Prostaglandins Leukot Essent Fatty Acids 2013;89:327-33.

96. Gould JF, Makrides M, Colombo J, et al. Randomized controlled trial of maternal omega-3 long-chain PUFA supplementation during pregnancy and early childhood development of attention, working memory, and inhibitory control. Am J Clin Nutr 2014;99:851-9.

97. Colombo J, Gustafson KM, Gajewski BJ, et al. Prenatal DHA supplementation and infant attention. Pediatr Res 2016;80:656-62.

98. Sastry PS. Lipids of nervous tissue: composition and metabolism. Prog Lipid Res 1985;24:69-176.

99. Mcllwain H, Bachelard HS. Biochemistry and the central nervous system. Edinburgh: Churchill Livingstone, 1985.

100. Uauy R, Dangour AD. Nutrition in brain development and aging: role of essential fatty acids. Nutr Rev 2006;64(5 Pt 2):24-33.

101. Feller SE, Gawrisch K, MacKerell AD. Polyunsaturated fatty acids in lipid bilayers: intrinsic and environmental contributions to their unique physical properties. J Am Chem Soc 2002;124:318-26.

102. Bourre JM, Francois M, Youyou A, et al. The effects of dietary alpha-linolenic acid on the composition of nerve membranes, enzymatic activity, amplitude of electrophysiological parameters, resistance to poisons and performance of learning tasks in rats. $J$ Nutr 1989;119:1880-92.

103. Lands WE, Morris A, Libelt B. Quantitative effects of dietary polyunsaturated fats on the composition of fatty acids in rat tissues. Lipids 1990;25:505-16.

104. Martinez M. Tissue levels of polyunsaturated fatty acids during early human development. J Pediatr 1992;120(4 Pt 2):S129-38.

105. Bazan NG, Scott BL. Dietary omega-3 fatty acids and accumulation of docosahexaenoic acid in rod photoreceptor cells of the retina and at synapses. Ups J Med Sci Suppl 1990;48:97-107.

106. Bowen RA, Clandinin MT. Dietary low linolenic acid compared with docosahexaenoic acid alter synaptic plasma membrane phospholipid fatty acid composition and sodium-potassium ATPase kinetics in developing rats. J Neurochem 2002;83:764-74.

107. Sarkadi-Nagy E, Wijendran V, Diau GY, et al. The influence of prematurity and long chain polyunsaturate supplementation in 4 -week adjusted age baboon neonate brain and related tissues. Pediatr Res 2003;54:244-52.

108. Lozada LE, Desai A, Kevala K, et al. Perinatal brain docosahexaenoic acid concentration has a lasting impact on cognition in mice. J Nutr 2017;147:1624-30.

109. Abedin L, Lien EL, Vingrys AJ, et al. The effects of dietary alphalinolenic acid compared with docosahexaenoic acid on brain, retina, liver, and heart in the guinea pig. Lipids 1999;34:475-82.

110. Moriguchi T, Greiner RS, Salem N. Behavioral deficits associated with dietary induction of decreased brain docosahexaenoic acid concentration. J Neurochem 2000;75:2563-73.

111. Levant B, Radel JD, Carlson SE. Decreased brain docosahexaenoic acid during development alters dopamine-related behaviors in adult rats that are differentially affected by dietary remediation. Behav Brain Res 2004;152:49-57.

112. Pawlosky RJ, Denkins Y, Ward G, et al. Retinal and brain accretion of long-chain polyunsaturated fatty acids in developing felines: the effects of corn oil-based maternal diets. Am J Clin Nutr 1997;65:465-72.

113. Auestad N, Innis SM. Dietary n-3 fatty acid restriction during gestation in rats: neuronal cell body and growth-cone fatty acids. Am J Clin Nutr 2000;71-312S-4.

114. Galli C, Trzeciak HI, Paoletti R. Effects of dietary fatty acids on the fatty acid composition of brain ethanolamine phosphoglyceride: reciprocal replacement of $n-6$ and $n-3$ polyunsaturated fatty 
acids. Biochimica et biophysica acta. Lipids and lipid Metab 1971;248:449-54.

115. Aïd S, Vancassel S, Poumès-Ballihaut $C$, et al. Effect of a dietinduced $\mathrm{n}-3$ PUFA depletion on cholinergic parameters in the rat hippocampus. J Lipid Res 2003;44:1545-51.

116. Catalan J, Moriguchi T, Slotnick B, et al. Cognitive deficits in docosahexaenoic acid-deficient rats. Behav Neurosci 2002;116:1022-31.

117. Takeuchi T, Fukumoto $Y$, Harada E. Influence of a dietary n-3 fatty acid deficiency on the cerebral catecholamine contents, EEG and learning ability in rat. Behav Brain Res 2002;131:193-203.

118. Champoux M, Hibbeln JR, Shannon C, et al. Fatty acid formula supplementation and neuromotor development in rhesus monkey neonates. Pediatr Res 2002;51:273-81.

119. Ahmad A, Murthy M, Greiner RS, et al. A decrease in cell size accompanies a loss of docosahexaenoate in the rat hippocampus. Nutr Neurosci 2002;5:103-13.

120. Clandinin MT, Chappell JE, Heim T, et al. Fatty acid utilization in perinatal de novo synthesis of tissues. Early Hum Dev 1981;5:355-66.

121. Daniels JL, Longnecker MP, Rowland AS, et al. Fish intake during pregnancy and early cognitive development of offspring. Epidemiology 2004;15:394-402.

122. Gale CR, Robinson SM, Godfrey KM, et al. Oily fish intake during pregnancy - association with lower hyperactivity but not with higher full-scale IQ in offspring. J Child Psychol Psychiatry 2008;49:1061-8.

123. Mendez MA, Torrent M, Julvez J, et al. Maternal fish and other seafood intakes during pregnancy and child neurodevelopment at age 4 years. Public Health Nutr 2009;12:1702-10.

124. Hanebutt FL, Demmelmair H, Schiessl B, et al. Long-chain polyunsaturated fatty acid (LC-PUFA) transfer across the placenta. Clin Nutr 2008;27:685-93.

125. Haggarty P, Page K, Abramovich DR, et al. Long-chain polyunsaturated fatty acid transport across the perfused human placenta. Placenta 1997;18:635-42.

126. Burdge GC, Calder PC. Conversion of alpha-linolenic acid to longer-chain polyunsaturated fatty acids in human adults. Reprod Nutr Dev 2005;45:581-97.

127. Clandinin MT, Chappell JE, Leong S, et al. Extrauterine fatty acid accretion in infant brain: implications for fatty acid requirements. Early Hum Dev 1980:4:131-8.

128. World Health Organisation (WHO). Born too soon: the global action report on preterm birth. Geneva: World Health Organisation, 2012.

129. Aylward GP. Cognitive and neuropsychological outcomes: more than IQ scores. Ment Retard Dev Disabil Res Rev 2002;8:234-40.

130. Wilson-Costello D, Friedman H, Minich N, et al. Improved neurodevelopmental outcomes for extremely low birth weight infants in 2000-2002. Pediatrics 2007;119:37-45.

131. Bhutta AT, Cleves MA, Casey PH, et al. Cognitive and behavioral outcomes of school-aged children who were born preterm: a metaanalysis. JAMA 2002;288:728-37.

132. Aarnoudse-Moens CS, Weisglas-Kuperus N, Duivenvoorden HJ, et al. Executive function and IQ predict mathematical and attention problems in very preterm children. PLoS One 2013;8:e55994.

133. Aarnoudse-Moens CS, Weisglas-Kuperus N, van Goudoever JB, et al. Meta-analysis of neurobehavioral outcomes in very preterm and/ or very low birth weight children. Pediatrics 2009;124:717-28.

134. Johnson S. Cognitive and behavioural outcomes following very preterm birth. Semin Fetal Neonatal Med 2007;12:363-73.

135. Lindström K, Lindblad F, Hiern A. Preterm birth and attentiondeficit/hyperactivity disorder in schoolchildren. Pediatrics 2011:127:858-65.

136. Arpi E, Ferrari F. Preterm birth and behaviour problems in infants and preschool-age children: a review of the recent literature. Dev Med Child Neurol 2013;55:788-96.

137. Spittle AJ, Treyvaud K, Doyle LW, et al. Early emergence of behavior and social-emotional problems in very preterm infants. J Am Acad Child Adolesc Psychiatry 2009;48:909-18.

138. van de Weijer-Bergsma E, Wijnroks L, Jongmans MJ. Attention development in infants and preschool children born preterm: a review. Infant Behav Dev 2008;31:333-51.

139. Kerr-Wilson CO, Mackay DF, Smith GC, et al. Meta-analysis of the association between preterm delivery and intelligence. $J$ Public Health 2012;34:209-16.

140. Aylward GP. Neurodevelopmental outcomes of infants born prematurely. J Dev Behav Pediatr 2005;26:427-40.
141. Blencowe H, Lee AC, Cousens S, et al. Preterm birth-associated neurodevelopmental impairment estimates at regional and global levels for 2010. Pediatr Res 2013;74(Suppl 1):17-34.

142. Haggarty P. Placental regulation of fatty acid delivery and its effect on fetal growth--a review. Placenta 2002;23(Suppl A):S28-38.

143. Clandinin MT, Van Aerde JE, Merkel KL, et al. Growth and development of preterm infants fed infant formulas containing docosahexaenoic acid and arachidonic acid. J Pediatr 2005;146:461-8.

144. Fewtrell MS, Morley R, Abbott RA, et al. Double-blind, randomized trial of long-chain polyunsaturated fatty acid supplementation in formula fed to preterm infants. Pediatrics 2002;110(1 Pt 1):73-82.

145. Fewtrell MS, Abbott RA, Kennedy K, et al. Randomized, doubleblind trial of long-chain polyunsaturated fatty acid supplementation with fish oil and borage oil in preterm infants. $J$ Pediatr 2004;144:471-9.

146. O'Connor DL, Hall R, Adamkin D, et al. Growth and development in preterm infants fed long-chain polyunsaturated fatty acids: a prospective, randomized controlled trial. Pediatrics 2001:108:359-71

147. Vanderhoof J, Gross S, Hegyi T, et al. Evaluation of a longchain polyunsaturated fatty acid supplemented formula on growth, tolerance, and plasma lipids in preterm infants up to 48 weeks postconceptional age. J Pediatr Gastroenterol Nutr 1999;29:318-26.

148. Birch EE, Birch DG, Hoffman DR, et al. Dietary essential fatty acid supply and visual acuity development. Invest Ophthalmol Vis Sci 1992:33:3242-53

149. Carlson SE, Werkman SH, Tolley EA. Effect of long-chain n-3 fatty acid supplementation on visual acuity and growth of preterm infants with and without bronchopulmonary dysplasia. Am J Clin Nutr 1996;63:687-97.

150. Carlson SE, Cooke RJ, Werkman SH, et al. First year growth of preterm infants fed standard compared to marine oil n-3 supplemented formula. Lipids 1992;27:901-7.

151. Carlson SE, Werkman SH, Rhodes PG, et al. Visual-acuity development in healthy preterm infants: effect of marine-oil supplementation. Am J Clin Nutr 1993;58:35-42.

152. Moon K, Rao SC, Schulzke SM, et al. Longchain polyunsaturated fatty acid supplementation in preterm infants. Cochrane Database Syst Rev 2016;12:Cd000375.

153. Smithers LG, Markrides M, Gibson RA. Human milk fatty acids from lactating mothers of preterm infants: a study revealing wide intraand inter-individual variation. Prostaglandins Leukot Essent Fatty Acids 2010;83:9-13.

154. Collins CT, Gibson RA, Makrides M, et al. The N3RO trial: a randomised controlled trial of docosahexaenoic acid to reduce bronchopulmonary dysplasia in preterm infants $<29$ weeks' gestation. BMC Pediatr 2016;16:72.

155. Collins CT, Makrides M, McPhee AJ, et al. Docosahexaenoic acid and bronchopulmonary dysplasia in preterm infants. N Engl J Med 2017;376:1245-55

156. Anderson PJ. Neuropsychological outcomes of children born very preterm. Sem Fetal Neonat Med 2014;19:90-6.

157. Lapillonne A, Eleni dit Trolli S, Kermorvant-Duchemin E. Postnatal docosahexaenoic acid deficiency is an inevitable consequence of current recommendations and practice in preterm infants. Neonatology 2010;98:397-403.

158. Lapillonne A, Groh-Wargo S, Gonzalez CH, et al. Lipid needs of preterm infants: updated recommendations. J Pediatr 2013;162(3 Suppl):S37-47.

159. Frankenburg WK, Coons $C E$. Home screening questionnaire: its validity in assessing home environment. J Pediatr 1986;108:624-6.

160. Makrides M, Gibson RA, McPhee AJ, et al. Neurodevelopmental outcomes of preterm infants fed high-dose docosahexaenoic acid: a randomized controlled trial. JAMA 2009;301:175-82.

161. Gould JF, Treyvaud K, Yelland LN, et al. Seven-year follow-up of children born to women in a randomized trial of prenatal DHA supplementation. JAMA 2017;317:1173-5.

162. Collins CT, Gibson RA, Anderson PJ, et al. Neurodevelopmental outcomes at 7 years' corrected age in preterm infants who were fed high-dose docosahexaenoic acid to term equivalent: a follow-up of a randomised controlled trial. BMJ Open 2015;5:e007314.

163. Ramakrishnan U, Gonzalez-Casanova I, Schnaas L, et al. Prenatal supplementation with DHA improves attention at 5 y of age: a randomized controlled trial. Am J Clin Nutr 2016;104-1075-82. 